\title{
TRPP2 Enhances Metastasis by Regulating Epithelial-Mesenchymal Transition in Laryngeal Squamous Cell Carcinoma
}

\author{
Kaile Wu ${ }^{a}$ Bing Shen ${ }^{b}$ Feifei Jiang ${ }^{b, c}$ Lin Xia $^{b}$ Taotao Fan ${ }^{b}$ Maolin Qin ${ }^{a}$ \\ Lianqiang Yang $^{d}$ Jizheng Guo ${ }^{b}$ Yifan Lia Min Zhu ${ }^{\mathrm{e}}$ Juan Du ${ }^{\mathrm{b}}$ Yehai Liu ${ }^{\mathrm{a}}$ \\ aDepartment of Otorhinolaryngology, Head and Neck Surgery, the First Affiliated Hospital of Anhui \\ Medical University, Hefei, ${ }^{b}$ Department of Physiology, School of Basic Medical Sciences, Anhui Medical \\ University, Hefei, 'Department of Pediatrics, The people's hospital of Bozhou, Bozhou, dDepartment of \\ Mathematics, School of Mathematical Sciences, Anhui University, Hefei, eHefei Institutes of Science, \\ Chinese Academy of Sciences, Hefei, China
}

\section{Key Words}

TRPP2 - Laryngeal squamous cell carcinoma • Epithelial-mesenchymal transition • Metastasis - Smad4 • STAT3

\begin{abstract}
Background/Aim: Surgery and chemotherapy treatments of human laryngeal squamous cell carcinoma (HLSCC) may fail due to metastasis, in which epithelial-mesenchymal transition (EMT) plays an important role. TRPP2, a nonselective cation channel, is expressed in various cell types and participates in many biological processes. Here, we show that TRPP2 enhanced metastasis by regulating EMT. Methods: We used immunohistochemistry, western blotting, $\mathrm{Ca}^{2+}$ imaging, transwell and wound healing assays to investigate TRPP2 expression levels in HLSCC tissue, and the role of TRPP2 in invasion and metastasis of a human laryngocarcinoma cell line (Hep2 cell). Results: We found that TRPP2 protein expression levels were significantly increased in HLSCC tissue; higher TRPP2 levels were associated with decreased patient survival time and degree of differentiation and advanced clinical stage. Knockdown of TRPP2 by transfection with TRPP2 siRNA markedly suppressed ATP-induced $\mathrm{Ca}^{2+}$ release, wound healing, and cell invasion in Hep2 cells. Moreover, TRPP2 siRNA significantly decreased vimentin expression but increased E-cadherin expression in Hep2 cells. In the EMT signalling pathway, TRPP2 siRNA significantly decreased Smad4, STAT3, SNAIL, SLUG and TWIST expression in Hep2 cells. Conclusion: We revealed a previously unknown function of TRPP2 in cancer development and a TRPP2-dependent mechanism underlying laryngocarcinoma cell invasion and metastasis. Our results suggest that TRPP2 may be used as a biomarker for evaluating patient prognosis and as a novel therapeutic target in HLSCC.
\end{abstract}




\section{Cellular Physiology Cell Physiol Biochem 2016;39:2203-2215 \\ \begin{tabular}{ll|l} 
and BiOChemistry & $\begin{array}{l}\text { DOI: 10.1159/000447914 } \\
\text { Published online: Novmber 07, } 2016\end{array}$ & $\begin{array}{l}\text { C } 2016 \text { The Author(s). Published by S. Karger AG, Basel } \\
\text { www.karger.com/cpb }\end{array}$
\end{tabular} \\ Wu et al.: TRPP2 Enhances HLSCC Metastasis}

\section{Introduction}

TRPP2 (transient receptor potential polycystic 2, previously known as polycystin-2, PC2, or PKD2), a nonselective cation channel encoded by the PKD2 gene, consists of four subunits, each including six transmembrane domains, and is located mainly in the endoplasmic membrane and plasma membranes with high $\mathrm{Ca}^{2+}$ permeability $[1,2]$. Previous studies have determined that TRPP2 interacts with polycystin-1 (PKD1) in the plasma membrane as a functional ion channel for cell adhesion and mechanosensation [3]. TRPP2 can be activated by epidermal growth factor (EGF) in the kidney epithelial cell line LLC-PK1 via coupling with the EGF receptor (EGFR), although a specific agonist or antagonist of TRPP2 remains unknown [4]. It is reported that TRPP2 contributes to the myogenic response in cerebral arteries [5]. Endoplasmic reticulum-resident TRPP2 reduces the $\mathrm{Ca}^{2+}$ release from the endoplasmic reticulum upon apoptotic stimuli, thus protecting the cells from apoptosis [6]. However, the TRPP2 and PKD1 complex can exert its effect on the kidney epithelium in the pathway that controls epithelial proliferation, differentiation and apoptosis via regulating intracellular $\mathrm{Ca}^{2+}$ [7]. TRPP2 is not only identified as a likely mutant target responsible for autosomal dominant polycystic kidney disease (ADPKD), but also widely expressed in various cells and participates in many activities relating to proliferation and differentiation, such as those involved in Alzheimer's disease, myocardial hypertrophy, arterial hypertension, and tumour formation [5, 8-13].

Head and neck cancer is the sixth most common carcinoma worldwide, severely deteriorating the health of elderly people $[14,15]$. Laryngeal squamous cell carcinoma, one of the most common tumours in head and neck cancer, has a poor prognosis due to its uncontrolled invasion and metastasis under the presently available treatments, including surgery and chemotherapy. Recently, epithelial-mesenchymal transition (EMT) has been suggested to play an important role in the invasion and metastasis of cancer cells derived from epithelia [16]. According to the results of previous reports, during EMT, cells that have lost their junction proteins have disturbed cellular polarity, rebuilt cytoskeletal protein, and destroyed intercellular adhesion [17]. In addition, cells undergoing EMT express more mesenchymal markers, such as vimentin and $\alpha$-smooth muscle actin ( $\alpha$-SMA), so that they acquire the capacity to invade adjacent normal tissues and spread to distant sites via blood or lymphatic vessels [18]. According to previously published studies, head and neck squamous cell carcinoma (HNSCC) as well as breast cancer are associated with EMT [1921]. One of the markers of cells involved in EMT is cadherin (named for $\mathrm{Ca}^{2+}$-dependent adhesion), a protein superfamily. Cadherin constitutes the extracellular $\mathrm{Ca}^{2+}$ binding domain, transmembrane proteins, and intracellular tails associated with a large number of adaptors and signalling proteins. Epithelial cadherin (E-cadherin), a member of the cadherin superfamily, is expressed by various cells during normal individual development [22]. After development, E-cadherin is responsible for tissue structure and cellular movement [22]. However, decreasing expression of E-cadherin is a critical factor in EMT processes and is associated with increased tumour cell invasion and metastasis [18]. Moreover, E-cadherin is thought by pathologists to be a prognostic indicator of many carcinomas because reduced E-cadherin expression parallels enhanced aggressiveness and dedifferentiation [18, 23]. Neural cadherin (N-cadherin) is thought to mediate growth cone motility in neurons [24]. However, different signalling pathways appear to be involved in EMT [25-27]. Unequivocally, transforming growth factor- $\beta$ (TGF- $\beta$ ) is a major inducer of different subtypes of EMT, including development, fibrosis, and carcinogenesis, in various cells [28]. In particular, TGF- $\beta$ plays a major role in carcinoma progression into a motile, invasive state in which cells migrate and form a metastasis during tumour development, whereas in the early stages of tumour growth, TGF- $\beta$ may have a tumour suppressive effect by inducing growth arrest and apoptosis $[18,28,29]$. Hence, as natural intracellular receptors of TGF- $\beta$, many Smad proteins, such as Smad2, Smad3 and Smad4, are phosphorylated after TGF- $\beta$ binding to regulate the transcription of related genes and may participate in EMT as well $[28,29]$. In addition, previous reports have indicated that the transcription factor signal transducer and 


\section{Cellular Physiology Cell Physiol Biochem 2016;39:2203-2215 \begin{tabular}{l|l|l}
\hline and Biochemistry $10.1159 / 000447914$ & $\begin{array}{l}\text { C) } 2016 \text { The Author(s). Published by S. Karger AG, Basel } \\
\text { www.karger.com/cpb }\end{array}$ \\
\hline
\end{tabular} \\ Wu et al.: TRPP2 Enhances HLSCC Metastasis}

activator of transcription 3 (STAT3) can induce EMT in cancer cells through activation of TWIST gene expression by cooperating with the EGFR [30]. STAT3 has also been found to be involved in many types of cancers, such as breast and prostate cancers [25,26]. Given all this evidence, we selected vimentin, E-cadherin, Smad4, and STAT3 as markers of the signalling pathway of EMT in the present study.

EMT is substantially involved in HNSCC [19]. TRPP2 likely participates in EMT and tumour metastasis. Thus, we hypothesise here for the first time that TRPP2 plays a role in regulating the proliferation, metastasis, and invasion of human laryngeal squamous cell carcinoma (HLSCC). A strong understanding of TRPP2 and its networking pathways regulating HLSCC metastasis would greatly assist in selecting drug combinations for treating such tumours. Here, we used immunohistochemical staining, western blotting, $\mathrm{Ca}^{2+}$ imaging, small interfering (si)RNA transfection, and cell migration and invasion assays to test our hypothesis.

\section{Materials and Methods}

\section{Cell culture}

Hep2, a laryngeal squamous cell carcinoma line, was purchased from the American Type Culture Collection (Manassas, VA, USA) and maintained in Dulbecco's modified Eagle's medium (DMEM) supplemented with $10 \%$ foetal bovine serum (FBS) at $37{ }^{\circ} \mathrm{C}$ in a $5 \% \mathrm{CO}_{2}$ incubator. siRNA transfections were facilitated by Lipofectamine 2000. One day before the transfection, Hep2 was plated in six-well culture plates with FBS-free and antibiotic-free culture medium. Before the transfection, culture medium (500 $\mu \mathrm{L}$ ) was added to each well. The confluency of the cells was controlled so that cells were approximately $80 \%$ confluent at the time of the transfection. The siRNA oligomer $(200 \mathrm{nM})$ was diluted in $50 \mu \mathrm{L}$ of Opti-MEM reduced-serum medium. Lipofectamine $2000(2 \mu \mathrm{L})$ was diluted in $50 \mu \mathrm{L}$ of Opti-MEM medium before use. After a 5-min incubation, the diluted siRNA oligomer and diluted Lipofectamine 2000 were combined, mixed, and incubated together for $20 \mathrm{~min}$ at room temperature. Finally, the siRNA-Lipofectamine 2000 complexes were added to the wells to transfect the cells. The medium was changed to that previously used (DMEM containing FBS) after $6 \mathrm{~h}$. A western blotting assay was used to determine the transfection efficiency after $24 \mathrm{~h}$.

\section{Western blotting}

Western blotting was performed as previously described [5]. The proteins were extracted from the lysates of Hep2 cells with a detergent extraction buffer that consisted of $50 \mathrm{mM}$ Tris- $\mathrm{HCl}$ (pH 7.4), 150 $\mathrm{mM} \mathrm{NaCl}, 1 \mathrm{mM} \mathrm{Na}{ }_{2}$ EDTA, $1 \%$ Triton X-100, $1 \%$ sodium deoxycholate, $0.1 \%$ SDS, sodium orthovanadate, sodium fluoride and leupeptin. Total proteins $(30 \mu \mathrm{g})$ were loaded into each pocket of a $10 \%$ SDS-PAGE gel. Subsequently, we transferred the protein to a polyvinylidene difluoride membrane. Membranes with proteins were incubated with Tris-buffered saline tween containing $10 \%$ non-fat dried milk for $1 \mathrm{~h}$ at room temperature to block nonspecific binding sites. For immunoblots, the membrane containing the transferred proteins was incubated with their respective specific primary antibodies (sc-25749 for TRPP2, sc-373717 for vimentin, sc-8426 for E-cadherin, sc-393933 for N-cadherin, sc-482 for STAT3, sc-7966 for Smad4, sc-393172 for SNAIL, sc-166476 for SLUG, sc-15393 for TWIST; Santa Cruz Biotechnology, USA) (1:200) overnight at $4{ }^{\circ} \mathrm{C}$ and then incubated with horseradish peroxidase-conjugated secondary antibody. The immunosignal results were revealed using an ECL detection system (Thermo Fisher Scientific, Pittsburgh, PA, USA). The optical densities of protein bands were analysed by a free software Image J. All protein bands were normalized to $\beta$-tubulin located in the same lane and expressed as the relative optical density.

\section{Immunohistochemistry}

Human laryngeal carcinoma tissues from patients were obtained during clinical surgery. Specimens were collected with written informed consent from each participating patient and approval by Ethics Committee of Anhui Medical University. The procedures were performed consistent with the Declaration of Helsinki and Good Clinical Practice [15]. The surgical specimens were fixed with 4\% paraformaldehyde and then sliced into 5- $\mu \mathrm{m}$ thick sections. The sections were deparaffinized and rehydrated. Subsequently, 


\section{Cellular Physiology Cell Physiol Biochem 2016;39:2203-2215

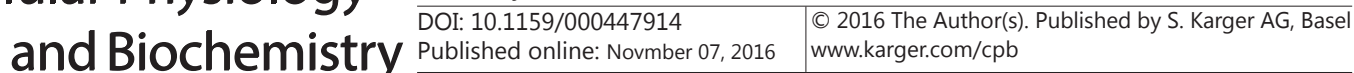 \\ Wu et al.: TRPP2 Enhances HLSCC Metastasis}

heat-mediated antigen retrieval was completed with citrate buffer in a microwave oven. Following a 10-min hydrogen peroxide (3\%) incubation, endogenous peroxidase activity was destroyed. The incubation with an anti-TRPP2 antibody (sc-25749, Santa Cruz Biotechnology, USA) overnight at $4{ }^{\circ} \mathrm{C}$ was followed by incubation with an anti-rabbit secondary antibody. The specimens were processed with horseradish peroxidase and then with 3,3'-diaminobenzidine tetrahydrochloride. Subsequently, the sections were counterstained with hematoxylin. The primary antibody was omitted as a negative control. Finally, all images were captured using a light microscope. Integrated optical density (IOD) of the images were analyzed by Image Pro Plus 5.1 (Media Cybernetics, USA) software.

\section{Wound healing assay}

Hep2 cells were seeded in a 6-well plate in a $5 \% \mathrm{CO}_{2}$ incubator at $37^{\circ} \mathrm{C}$ until confluent and then rinsed in PBS and cultured in low-serum medium (0.1\% serum in DMEM) one day before the experiment. A wound was produced by a straight scratch with a $200-\mu \mathrm{L}$ pipette tip. The pipette tip was kept at an angle of less than approximately 30 degrees to limit the width of the wound so that both wound edges could be imaged together. The Hep2 cells were then rinsed with PBS to remove the floating cells and cultured in normal medium supplemented with 10\% FBS. Finally, a microscope (Nikon company, Japan) was used to capture images at the same position of each well $0 \mathrm{~h}, 12 \mathrm{~h}$, and $24 \mathrm{~h}$ after the wound was created and at $37^{\circ} \mathrm{C}$. The relative distance of cell migration to the scratched area was measured (the wound area remaining after $24 \mathrm{~h}$ was subtracted from the original wound area at $0 \mathrm{~h}$ ), and a healing percentage was calculated. This experiment was repeated four times.

\section{Cell migration and invasion assay}

Transwell chambers containing polycarbonate membrane filters with an 24-well 8- $\mu$ m pore size (\#3422, Corning Company, USA) were coated with Matrigel (BD354277, Becton Dickinson Company, USA). In each well, $40 \mu \mathrm{l}$ of Matrigel was added to a insert and dried in a $37^{\circ} \mathrm{C}$ incubator for 30 minutes to form a thin gel layer. DMEM $(0.2 \mathrm{~mL})$ was added to the upper chamber containing Hep2 cells, and the same medium $(0.6 \mathrm{~mL})$ supplemented with $15 \%$ FBS was added to the lower chamber. Hep2 cells were seeded in the insert at a density of $1 \times 10^{5}$. Following a $48 \mathrm{~h}$ incubation in a $5 \% \mathrm{CO}_{2}$ incubator at $37^{\circ} \mathrm{C}$, we removed the transwell insert from the plate and used a cotton-tipped applicator to carefully rub off the remaining cells that have not migrated from the top of the membrane. The cells that had migrated through the membrane filter pores and stuck to the lower side of the filter membrane were fixed in paraformaldehyde and stained with 4', 6-diamidino-2-phenylindole (DAPI). Four randomly selected fields were captured using a fluorescence microscope (Nikon company, Japan) to calculate the number of cells that had successfully invaded and transmigrated the Matrigel. The results are expressed as the mean cell count of the four fields.

\section{Intracellular $\mathrm{Ca}^{2+}$ concentrations $\left(\left[\mathrm{Ca}^{2+}\right]_{i}\right)$ measurement}

The $\left[\mathrm{Ca}^{2+}\right]_{\mathrm{i}}$ was measured using methods described elsewhere [13]. Briefly, the seeded Hep2 cells were loaded with $10 \mu \mathrm{mol} / \mathrm{L}$ Fluo-8 (Invitrogen, USA) with 0.02\% pluronic acid F-127 (Sigma-Aldrich Co., USA) at $37^{\circ} \mathrm{C}$ for $30 \mathrm{~min}$. ATP $(100 \mu \mathrm{mol} / \mathrm{L})$ was used to evoke $\mathrm{Ca}^{2+}$ release in a $\mathrm{Ca}^{2+}$-free solution that contained (in mmol/L) $140 \mathrm{NaCl}, 1 \mathrm{MgCl}_{2}, 5 \mathrm{KCl}$, glucose, $0.2 \mathrm{EGTA}$, and 5 HEPES at pH 7.4. The change in fluorescence, which indicated a change in $\left[\mathrm{Ca}^{2+}\right]_{\mathrm{i}}$, was recorded using fluorescence microscopy (Nikon) analysis, with excitation and emission wavelengths of $488 \mathrm{~nm}$ and $515 \mathrm{~nm}$, respectively. The results of the $\left[\mathrm{Ca}^{2+}\right]_{\mathrm{i}}$ changes are shown as the ratio of the fluorescence intensity before and after the application of ATP $\left(\mathrm{F}_{1} / \mathrm{F}_{0}\right)$. The fluorescence ratio of one experiment was a mean from about 40 cells.

Statistical analysis

SigmaPlot software was used to perform the statistical analyses of two-tailed, unpaired Student's $t$-tests. All results are expressed as means \pm SEM. A value of $P<0.05$ was considered statistically significant.

\section{Results}

Increased TRPP2 expression in HLSCC tissues from patients

HLSCC tissues were obtained from patients undergoing clinical surgery. As an initial and broad screening method, immunohistochemical analysis was used to investigate TRPP2 protein expression levels in HLSCC and the adjacent tissues from each patient. The KARGER 

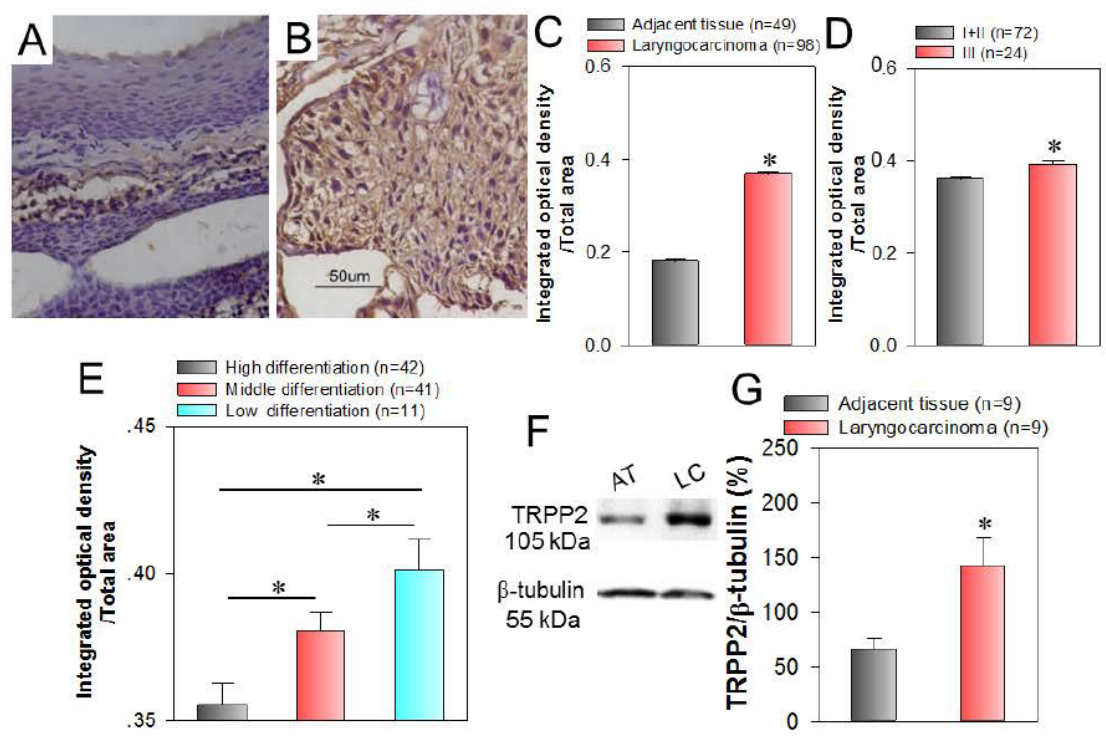

Fig. 1. TRPP2 protein expression levels in human laryngocarcinoma and adjacent tissues. A and B. Representative images of adjacent tissues (A) and laryngocarcinoma tissues (B) showing TRPP2 protein expression levels via immunohistochemical analysis. (C) Summarized data showing the ratio of integrated optical density/total area of TRPP2 immunostaining in human laryngocarcinoma and adjacent tissues. Thus, the staining results are normalized to the optical density of the total area. Values are shown as the mean \pm SEM ( $\mathrm{n}=49-98) .{ }^{*} P<0.05$ for laryngocarcinoma vs. adjacent tissues. ( $\mathrm{D}$ and $\mathrm{E}$ ) The relationship between clinical stage (D) or degree of differentiation (E) and TRPP2 expression level indicated by the ratio of integrated optical density/total area of TRPP2 immunostaining in human laryngocarcinoma and adjacent tissues. For the pathological standard, human laryngocarcinoma samples were classified into high, middle, and low differentiation levels. For the clinical standard, human laryngocarcinoma samples were classified into stages I, II, and III. Values are shown as the mean \pm SEM $(\mathrm{n}=11-72)$. In $\mathrm{D},{ }^{*} P<0.05$ for stages I+II vs. III. In E, ${ }^{*} P<$ 0.05 for high vs. middle or low differentiation, and for middle vs. low differentiation. (F) Representative images showing TRPP2 expression in adjacent tissue (AT) and laryngocarcinoma tissue (LC). (G) Summarized data showing TRPP2 expression levels in human laryngocarcinoma and adjacent tissues, with $\beta$-tubulin used as a loading control. Values are shown as the mean \pm SEM $(n=9)$. ${ }^{*} P<0.05$ for laryngocarcinoma vs. adjacent tissues.

results indicated that the TRPP2 protein expression level, represented as an IOD value, was significantly increased in HLSCC tissues compared with that in adjacent tissues (Fig. 1A-C). A western blot analysis performed to confirm this result also showed that HLSCC tissues expressed more TRPP2 protein than did the adjacent tissues (Fig. 1F-G).

The HLSCC specimens used in the immunohistochemical analysis were then classified using a clinical stage standard to investigate the relationship between the clinical stage and TRPP2 expression level. The results indicated that specimens in stage III expressed more TRPP2 protein than did specimens in both stages I and II together (Fig. 1D). We also used a pathophysiology standard to classify HLSCC specimens into three groups based on their degree of differentiation to investigate the relationship between differentiation degree and TRPP2 protein expression level. The analysis showed that each of the three groups was significantly different from the other two and that the TRPP2 protein expression level increased as differentiation was reduced (Fig. 1E). These results suggested that TRPP2 protein was highly expressed in HLSCC tissues, and that the TRPP2 expression level was positively correlated with clinical stage but negatively correlated with the degree of differentiation in HLSCC.

\section{KARGER}


Fig. 2. Correlation between TRPP2 protein expression level and patient survival. Kaplan-Meier curves for the overall survival of patients with laryngocarcinoma according to the expression of TRPP2. Based on the ratio of the integrated optical density/total area of TRPP2 immunostaining in laryngocarcinoma tissues, patients were included in either a low density $(<0.344)$ or high density $(>0.344)$ group . The survival status of each patient was obtained during follow-up. The survival rate-time curves are shown as a black line (density <0.344) and a red line (density $>0.344$ ).

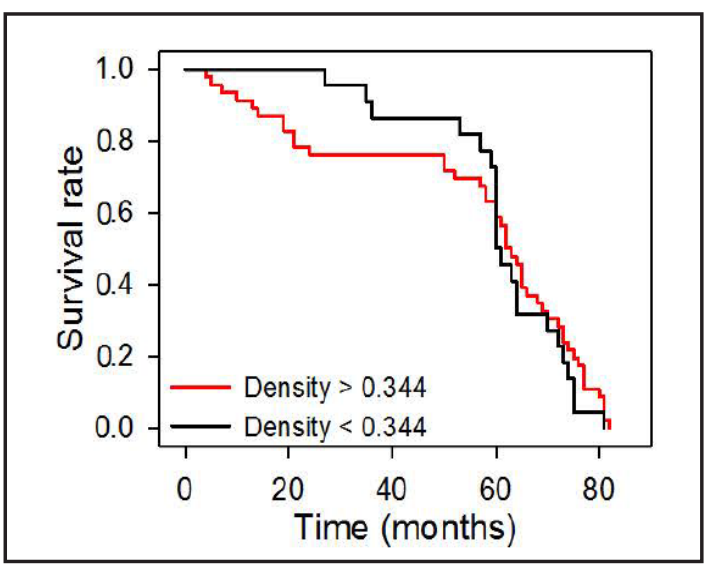

Fig. 3. Effect of TRPP2 siRNA on intracellular $\mathrm{Ca}^{2+}\left(\left[\mathrm{Ca}^{2+}\right]_{\mathrm{i}}\right)$ release in Hep2 cells. $\mathrm{A}$ and B. Representative images (A) and summarized data (B) showing TRPP2 expression levels in Hep2 cells transfected with scrambled or TRPP2 siRNA. The optical density of each protein was normalized to $\beta$-tubulin. (C and D) Representative traces (C) and summarized data (D) showing that ATP $(100 \mu \mathrm{mol} / \mathrm{L})$ increased $\left[\mathrm{Ca}^{2+}\right]_{\mathrm{i}}$ in Hep2 cells transfected with scrambled or TRPP2 siRNA and placed in a $\mathrm{Ca}^{2+}$-free solution. Values are shown as the mean \pm SEM $(\mathrm{n}=5-6) . * P$ $<0.05$ for scrambled siRNA vs. TRPP2 SiRNA.

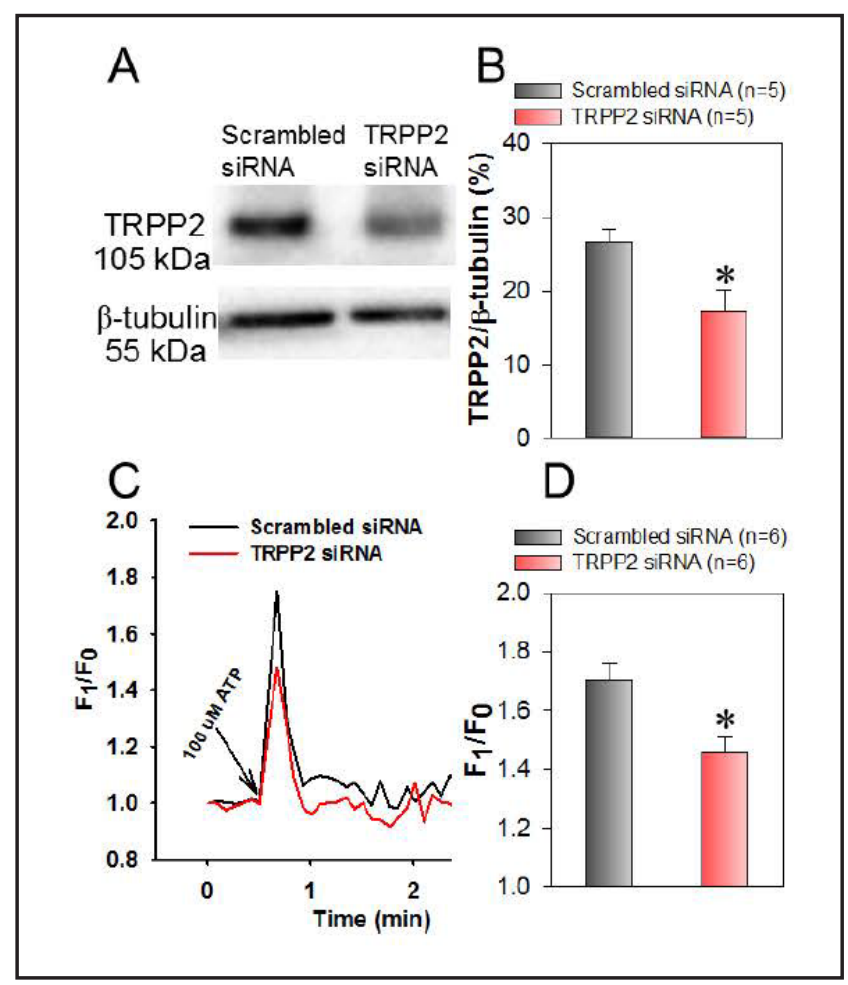

Correlation of patient survival time with level of TRPP2

To investigate the correlation between the TRPP2 protein expression level and patient survival, we examined survival times for those patients with HLSCC who provided the specimens that were used for immunohistochemical analysis of TRPP2. We used the linear regression models to fit the immunohistochemical IOD data to find the demarcation point (0.344), respectively. The patients were placed into one of two groups (lower or higher). We found that for a survival time of 0 to 60 months, patients in the lower IOD group (i.e., $<0.344$ ) lived significantly longer than those in the higher IOD group (i.e., $>0.344 ; P=0.0026$; Fig. 2). However, for survival times longer than 60 months, no statistical differences were detected between the two groups (Fig. 2). These results indicated that for the first 0-60 months, patients with HLSCC having higher TRPP2 protein expression levels had shorter survival times than those having lower TRPP2 levels.

Role of TRPP2 in laryngocarcinoma Hep2 cell $\mathrm{Ca}^{2+}$ release

TRPP2 is a nonselective cation channel permeable to $\mathrm{Ca}^{2+}$ and located in the endoplasmic reticulum membrane and the plasma membrane [1]. To identify the function of TRPP2 in 


\section{Cellular Physiology and Biochemistry

Fig. 4. Effect of TRPP2 siRNA on wound healing in Hep2 cells. A and B. Representative images (A) and summarized data (B) showing wound healing in Hep2 cells transfected with scrambled or TRPP2 siRNA at 12 and $24 \mathrm{~h}$. Values shown are the mean \pm SEM ( $\mathrm{n}=4$ ). ${ }^{*} P<0.05$ for scrambled siRNA vs. TRPP2 siRNA.
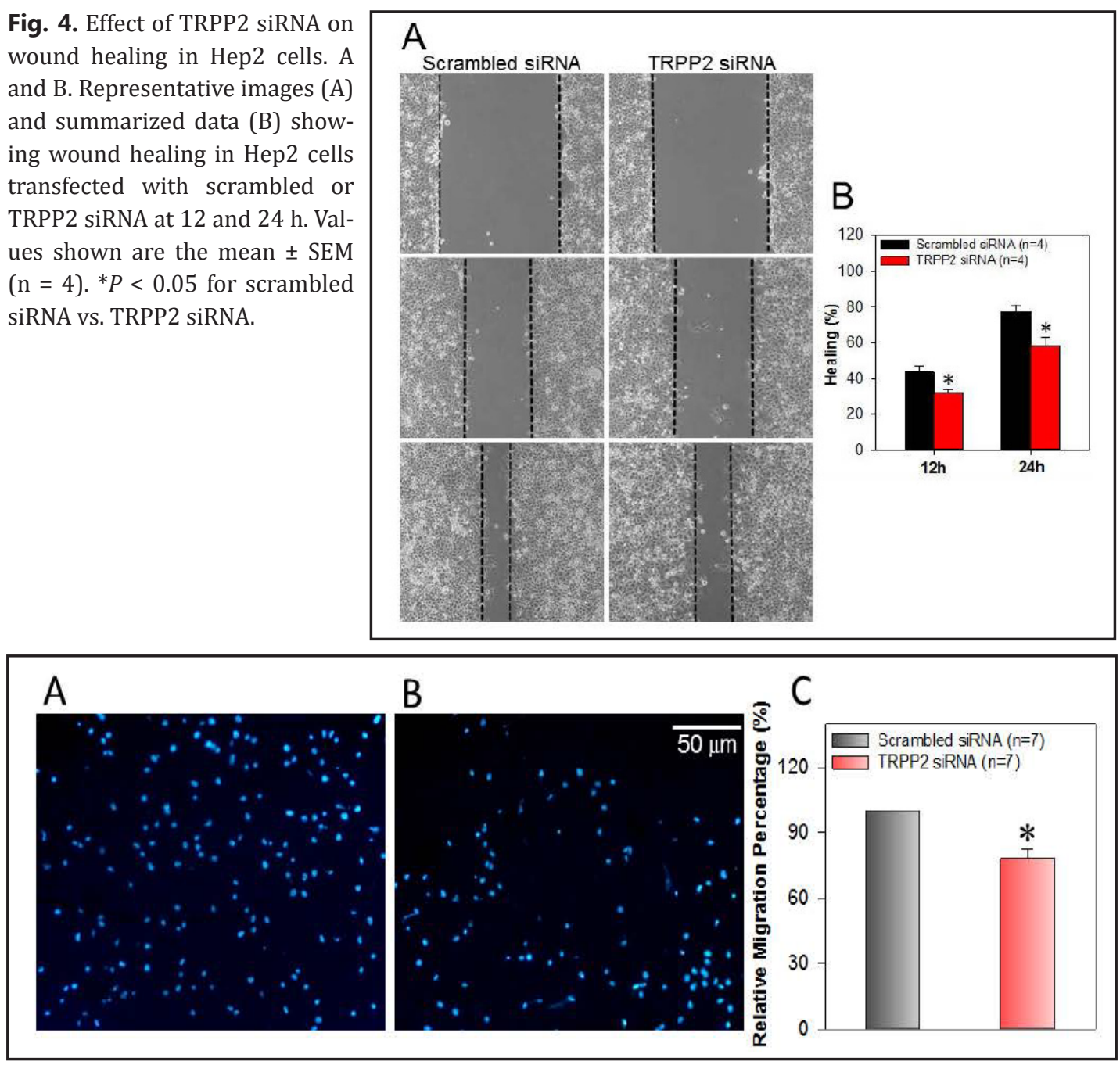

Fig. 5. Effect of TRPP2 siRNA on cell invasion in Hep2 cells. (A-C) Representative images (A and B) and summarized data (C) showing cell invasion in Hep2 cells transfected with (A) scrambled or (B) TRPP2 siRNA. The invaded cells moving through the matrix were stained with DAPI (blue). Values are shown as the mean \pm SEM $(\mathrm{n}=7) .{ }^{*} P<0.05$ for scrambled siRNA vs. TRPP2 siRNA.

Hep2 cells, we used a TRPP2-specific siRNA to suppress TRPP2 expression. Our western blot analysis indicated that TRPP2 siRNA successfully knocked down the expression of the TRPP2 protein (Fig. 3A-B). Subsequently, $\mathrm{Ca}^{2+}$ imaging was conducted to measure changes in $\left[\mathrm{Ca}^{2+}\right]_{i}$. Adenosine triphosphate (ATP) induces inositol 1,4,5-trisphosphate production by activating a purinergic $G$ protein-coupled receptor, the $\mathrm{P} 2 \mathrm{Y}$ receptor, in the plasma membrane. Our results showed that ATP $(100 \mu \mathrm{M})$ evoked $\mathrm{Ca}^{2+}$ release from $\mathrm{Ca}^{2+}$ stores and strongly induced $\left[\mathrm{Ca}^{2+}\right]_{\mathrm{i}}$ increase in Hep2 cells in a Ca ${ }^{2+}$-free medium (Fig. 3C-D). However, TRPP2 siRNA markedly suppressed the ATP-induced $\mathrm{Ca}^{2+}$ release (Fig. 3C-D). These results suggested that TRPP2 siRNA effectively suppressed TRPP2 expression and agonist-induced $\mathrm{Ca}^{2+}$ release in Hep2 cells.

Role of TRPP2 in Hep2 cell migration and invasion

Migration and invasion are two major factors determining the pathophysiological stage and the state of deterioration in patients with carcinomas [31] and are critically involved in laryngocarcinoma recidivating and metastasis. Thus, we used TRPP2 siRNA to identify the role of TRPP2 in Hep2 cell migration and invasion. When Hep2 cells were transfected with 


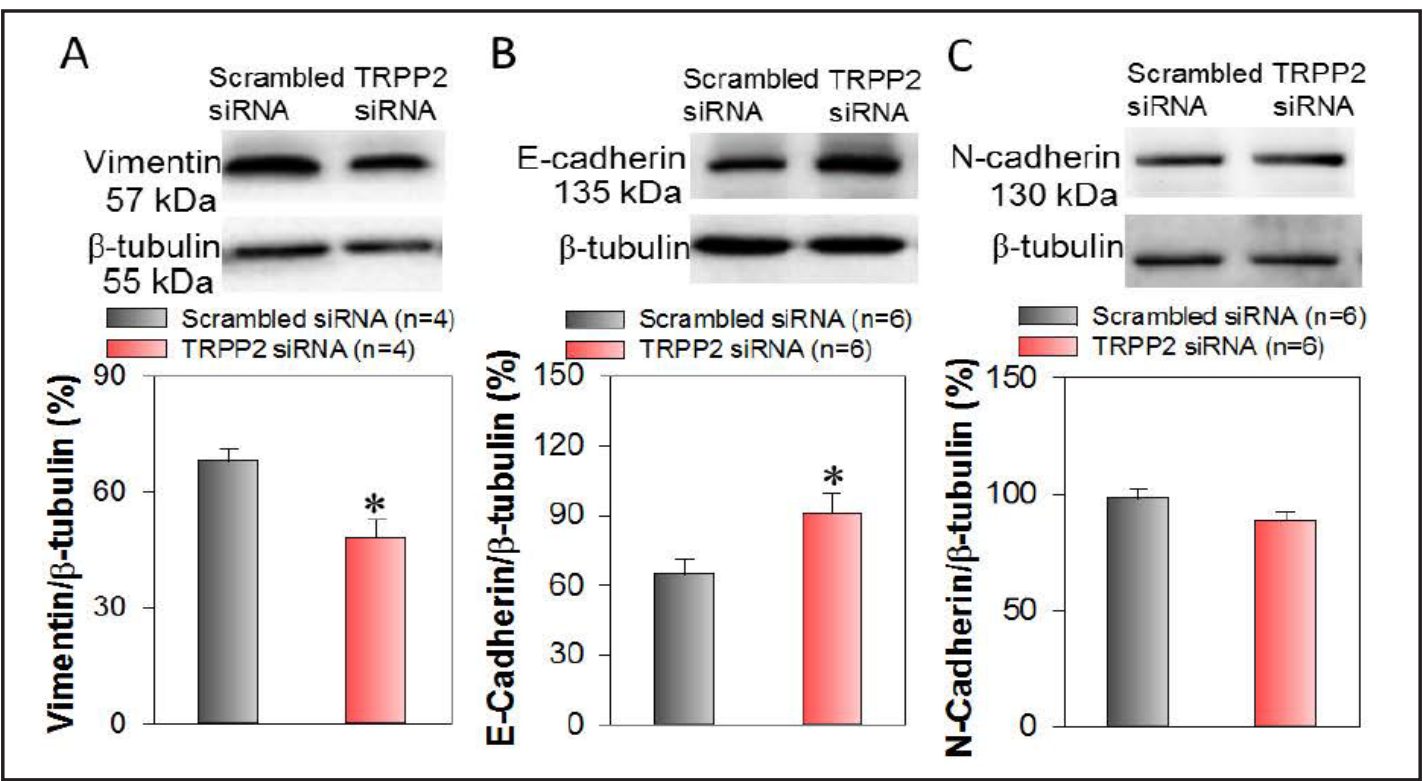

Fig. 6. Effects of TRPP2 siRNA on vimentin, E-cadherin and N-cadherin expression in Hep2 cells. (A-C) Representative western blot images and summarized data showing vimentin (A), E-cadherin (B) and Ncadherin (C) protein expression levels in Hep2 cells transfected with scrambled or TRPP2 siRNA. The optical density of each protein was normalized to $\beta$-tubulin. Values shown are the mean \pm SEM $(n=4-6)$. ${ }^{*} P<0.05$ for scrambled siRNA vs. TRPP2 siRNA.

TRPP2 siRNA, wound healing assay data indicated that their migration velocity markedly slowed down (Fig. 4). Compared with that for the scrambled siRNA-transfected control cells, TRPP2 siRNA significantly reduced the velocity of Hep2 cell migration both $12 \mathrm{~h}$ and $24 \mathrm{~h}$ after transfection (Fig. 4A-B).

To examine TRPP2 function in cell invasion, we cultured transfected Hep2 cells in Matrigel transwells with $8-\mu \mathrm{m}$ pores to allow the cells to digest the matrix and move. Compared with the scrambled control siRNA, Hep2 cells transfected with TRPP2 siRNA moved more slowly through the matrix (Fig. 5). These results indicated that TRPP2 participated in Hep2 cell migration and might promote Hep2 cells to secret digestive enzymes to enhance invasion and metastasis.

\section{Role of TRPP2 in Hep2 cell EMT and the underlying signalling pathway}

Vimentin and E-cadherin are two molecular markers for EMT [18]. During EMT, cells produce more vimentin but less E-cadherin. Therefore, E-cadherin is often selected as a prognostic marker for patients with many types of carcinomas. In our study, we used western blot analysis to elucidate the changes in vimentin, E-cadherin and $\mathrm{N}$-cadherin. We found that compared to that in cells transfected with scrambled siRNA, vimentin was decreased but E-cadherin was significantly increased in TRPP2 siRNA-transfected Hep2 cells without the alteration of N-cadherin (Fig. 6A-C), suggesting that TRPP2 was likely involved in the EMT process.

To further explore the EMT pathway related to TRPP2, we examined Smad4 and STAT3 protein expression levels in Hep2 cells. Compared with those in the scrambled control siRNA-transfected cells, the expression levels of both Smad4 and STAT3 were decreased in TRPP2 siRNA-transfected Hep2 cells (Fig. 7A-B). These data suggested that TRPP2 might participate in Hep2 cell EMT via Smad4- and STAT3-dependent pathways. Additionally, the expression levels of several transcription factors, including SNAIL, SLUG and TWIST were investigated. The result showed that the expression levels of SNAIL, SLUG and TWIST were significantly suppressed in TRPP2 siRNA-transfected Hep2 cells (Fig. 8A-C). 
Fig. 7. Effects of TRPP2 SiRNA on Smad4 and STAT3 expression in Hep2 cells. A and B. Representative western blot images and summarized data showing Smad4 (A) and STAT3 (B) protein expression levels in Hep2 cells transfected with scrambled or TRPP2 siRNA. The optical density of each protein was normalized to $\beta$-tubulin. Values shown are the mean \pm SEM ( $\mathrm{n}=$ 4-6). ${ }^{*} P<0.05$ for scrambled siRNA vs. TRPP2 siRNA.
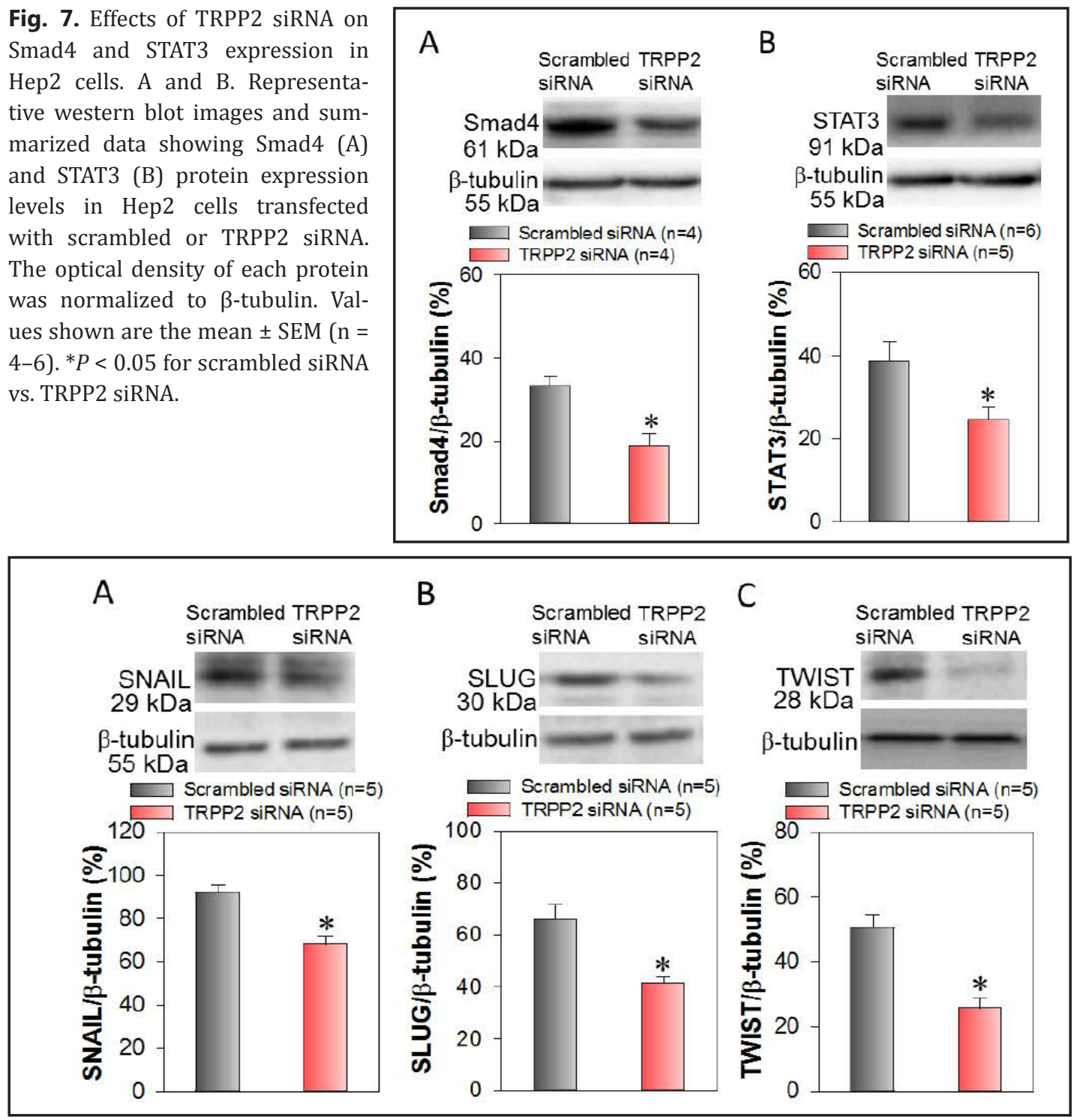

Fig. 8. Effects of TRPP2 siRNA on SNAIL, SLUG and TWIST expression in Hep2 cells. A-C. Representative western blot images and summarized data showing SNAIL (A), SLUG (B) and TWIST (C) protein expression levels in Hep2 cells transfected with scrambled or TRPP2 siRNA. The optical density of each protein was normalized to $\beta$-tubulin. Values shown are the mean \pm SEM $(n=5) .{ }^{*} P<0.05$ for scrambled siRNA vs. TRPP2 SiRNA.

\section{Discussion}

TRPP2, as a nonselective cation channel, is reportedly involved in several types of cancers, including breast and prostate cancers $[32,33]$. In the present study, we elucidated the relationship between the expression levels of TRPP2 protein in specimens obtained from patients during surgical procedures and the clinical prognosis of these patients. The potential pathological roles of TRPP2 and the underlying mechanisms were also investigated in laryngocarcinoma Hep2 cells. Here, we reported the four following novel findings. (1) Specimens with higher TRPP2 expression levels (as determined using immunohistochemistry and western blot analyses) had a lower degree of differentiation and a more advanced clinical stage. (2) Patients with specimens having higher TRPP2 expression levels displayed worse clinical prognosis and shorter 5-year survival times. (3) In Hep2 cells, transfection with TRPP2 


\section{Cellular Physiology Cell Physiol Biochem 2016;39:2203-2215

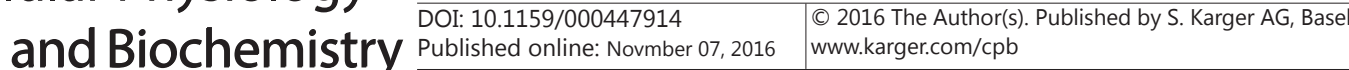 \\ Wu et al.: TRPP2 Enhances HLSCC Metastasis}

siRNA significantly reduced ATP-induced $\mathrm{Ca}^{2+}$ release, migration, and invasion compared with cells transfected with scrambled control siRNA. (4) TRPP2 siRNA markedly suppressed the expression levels of vimentin, Smad4, STAT3, SNAIL, SLUG and TWIST proteins in Hep2 cells, but increased E-cadherin expression without the alteration of $\mathrm{N}$-cadherin. Overall, our data suggest that a high expression of TRPP2 may accelerate the metastasis of laryngeal squamous cell carcinoma by enhancing EMT through Smad4 and STAT3 pathways.

HLSCC is one of the most common carcinomas in HNSCC. Both surgery and chemotherapy approaches are often used to treat patients with HLSCC. However, the prognosis and 5-year survival rate are unsatisfactory because of uncontrolled invasion and metastasis. Previous studies have indicated that some proteins can be used as prognosis and diagnostic biomarkers for HLSCC, such as p53, EGFR and TGF- $\alpha[34,35]$. In the present study, we found that the TRPP2 expression level was markedly higher in tumour tissues than in adjacent tissues. Our results investigating the correlation between TRPP2 protein expression level and clinical stage, differentiation degree, or survival time indicated that specimens expressing more TRPP2 had a lower degree of differentiation, more advanced clinical stage, and shorter 5 -year survival time. Hence, TRPP2 may be involved in the generation and deterioration of HLSCC, and can be considered a clinical diagnostic biomarker indicating early metastasis and prognosis for patients with HLSCC.

Metastasis, the process by which secondary tumours develop, is associated with EMT in which cell-cell contacts are lost and cellular phenotypes are changed. Recent accumulating evidence indicates that many types of ion channels are related to tumour EMT, especially $\mathrm{Ca}^{2+}$ channels [33]. Similar studies have also determined that chelation of intracellular $\mathrm{Ca}^{2+} \mathrm{can}$ suppress EGF-induced EMT [31]. Additionally, the transient receptor potential, melastatinlike 7 (TRPM7) channel is a $\mathrm{Ca}^{2+}$ permeable ion channel and is involved in breast cancer EMT [36]. The $\left[\mathrm{Ca}^{2+}\right]_{\mathrm{i}}$ has major effects on the cellular migration machinery. In the present study, $\mathrm{Ca}^{2+}$ was considered as a regulator of cell behaviours, such as EMT. TRPP2 is a nonselective $\mathrm{Ca}^{2+}$-permeable cation channel located at both cell membrane and endoplasmic reticulum. Hep2 cells transfected with TRPP2 siRNA showed a decrease in the amplitude of the signal representing $\mathrm{Ca}^{2+}$ released from the endoplasmic reticulum and decreased cell migration and invasion. Based on these novel findings, we propose that TRPP2 may participate in the regulation of intracellular $\mathrm{Ca}^{2+}$ signalling to regulate the EMT process and be included in the list of channels involved in cellular metastasis, along with TRPV1, 2 and 6, TRPM1 and 8, and TRPC6.

Previous studies have determined that epithelial tumours with EMT are likely to have strongly increased invasion, metastasis, and proliferation. E-cadherin, present in many types of epithelial cells, and vimentin, a mesenchymal substance, are both markers of EMT. In our study, when TRPP2 protein expression was suppressed via transfection with specific siRNA in Hep2 cells, we found a marked increase in E-cadherin and decrease in vimentin expression levels, which indicated inhibited EMT. N-cadherin was not altered in TRPP2 siRNA transfected Hep2 cells. Hence, EMT is implicated in the development of laryngocarcinoma as well as breast and prostate cancers. These results also provided a significant advance in understanding the effects of TRPP2 on EMT through its role in $\mathrm{Ca}^{2+}$ regulation. We suggest here for the first time that TRPP2 be added to the intricate network of EMT.

When EMT occurs, the expression of epithelial markers is suppressed, while the expression of mesenchymal markers is enhanced. This change is modulated via a series of factors, such as TGF- $\beta /$ Smad and STAT pathways. The TGF- $\beta /$ Smad pathway is associated with DNA methylation. A recent study has shown that disruption of TGF- $\beta /$ Smad can contribute to DNA demethylation, reversal of epithelial morphology, and inhibition of invasion in breast cancer cells [37]. STAT3 is an oncogenic transcription factor that is activated for EMT in many human malignancies, such as breast tumour. STAT3 can upregulate the TWIST gene to induce EMT in cancer cells [38] and play a vital role in cell proliferation, invasion, and metastasis. Our results showed that Smad4 and STAT3 were both decreased in Hep2 cells transfected with TRPP2 siRNA accompanied with decreased expression of SNAIL, SLUG and TWIST. These results indicated that TRPP2 channel maybe involved in these pathways by regulating 


\section{Cellular Physiology Cell Physiol Biochem 2016;39:2203-2215 \begin{tabular}{l|l} 
and Biochemistry & DOI: 10.1159/000447914 \\
Published online: Novmber 07, 2016 & $\begin{array}{l}\text { (c) 2016 The Author(s). Published by S. Karger AG, Basel } \\
\text { www.karger.com/cpb }\end{array}$
\end{tabular} \\ Wu et al.: TRPP2 Enhances HLSCC Metastasis}

$\mathrm{Ca}^{2+}$ homeostasis and that EMT was suppressed, consistent with reduced migration and metastasis. However, as we did not provide direct evidence to prove the $\mathrm{Ca}^{2+}$ involvement, we can only propose that the TRPP2 channel may regulate $\left[\mathrm{Ca}^{2+}\right]_{\mathrm{i}}$ to influence cancer cellcell contacts, invasion, metastasis, and the EMT process. This mechanism emphasizes the importance of TRPP2 in cancer advancement and metastasis, and indicates that TRPP2 is a potential target for clinical diagnosis and treatment of cancer.

In summary, we demonstrated that the TRPP2 protein expression level was significantly increased in human laryngeal carcinoma tissue and that its expression had an opposing relationship with the survival time of patients. Knockdown of TRPP2 markedly suppressed ATP-induced $\mathrm{Ca}^{2+}$ release, migration and invasion, and the EMT process in Hep2 cells. The present study revealed a previous unknown mechanism of TRPP2 underlying human laryngeal carcinoma invasion and metastasis. We propose the use of TRPP2 as a new biomarker to evaluate patient prognosis and as a novel potential therapeutic target in human laryngeal carcinoma.

\section{Acknowledgements}

We thank Mr. Dake Huang in the comprehensive Laboratory of School of Basic Medical Sciences in Anhui Medical University for technical support. This work was supported by Grants from National Natural Science Foundation of China (Grant No. 81371284, 81570403); Anhui Provincial Natural Science Foundation (Grant No. 1408085MH157); Science and Technology Research Project of Anhui Province (Grant No. 1501041147); Young Prominent Investigator Supporting Program from Anhui Medical University; Overseas Scholars Start Fund from Department of Human Resources and Social Security of Anhui Province.

\section{Disclosure Statement}

There is no conflict of interest.

\section{References}

1 Tsiokas L, Kim S, Ong EC: Cell biology of polycystin-2. Cell Signal 2007;19:444-453.

2 Tsiokas L: Function and regulation of TRPP2 at the plasma membrane. Am J Physiol Renal Physiol 2009;297:F1-9.

3 Giamarchi A, Feng S, Rodat-Despoix L, Xu Y, Bubenshchikova E, Newby LJ, Hao J, Gaudioso C, Crest M, Lupas AN, Honore E, Williamson MP, Obara T, Ong AC, Delmas P: A polycystin-2 (TRPP2) dimerization domain essential for the function of heteromeric polycystin complexes. Embo J 2010;29:1176-1191.

4 Ma R, Li WP, Rundle D, Kong J, Akbarali HI, Tsiokas L: PKD2 functions as an epidermal growth factoractivated plasma membrane channel. Mol Cell Biol 2005;25:8285-8298.

5 Zhao R, Zhou M, Li J, Wang X, Su K, Hu J, Ye Y, Zhu J, Zhang G, Wang K, Du J, Wang L, Shen B: Increased TRPP2 expression in vascular smooth muscle cells from high-salt intake hypertensive rats: The crucial role in vascular dysfunction. Mol Nutr Food Res 2015;59:365-372.

6 Wegierski T, Steffl D, Kopp C, Tauber R, Buchholz B, Nitschke R, Kuehn EW, Walz G, Kottgen M: TRPP2 channels regulate apoptosis through the $\mathrm{Ca} 2+$ concentration in the endoplasmic reticulum. Embo J 2009;28:490-499.

7 Anyatonwu GI, Ehrlich BE: Calcium signaling and polycystin-2. Biochem Biophys Res Commun 2004;322:1364-1373.

8 Mochizuki T, Wu G, Hayashi T, Xenophontos SL, Veldhuisen B, Saris JJ, Reynolds DM, Cai Y, Gabow PA, Pierides A, Kimberling WJ, Breuning MH, Deltas CC, Peters DJ, Somlo S: PKD2, a gene for polycystic kidney disease that encodes an integral membrane protein. Science 1996;272:1339-1342. 


\section{Cellular Physiology Cell Physiol Biochem 2016;39:2203-2215 \begin{tabular}{l|l|l|}
\hline and Biochemistry 10.1159/000447914 & $\begin{array}{l}\text { C) 2016 The Author(s). Published by S. Karger AG, Basel } \\
\text { www.karger.com/cpb }\end{array}$ \\
\hline
\end{tabular} \\ Wu et al.: TRPP2 Enhances HLSCC Metastasis}

9 Mene P, Punzo G, Pirozzi N: TRP channels as therapeutic targets in kidney disease and hypertension. Curr Top Med Chem 2013;13:386-397.

10 Naziroglu M: Molecular role of catalase on oxidative stress-induced $\mathrm{Ca}(2+)$ signaling and TRP cation channel activation in nervous system. J Recept Signal Transduct Res 2012;32:134-141.

11 Narayanan D, Bulley S, Leo MD, Burris SK, Gabrick KS, Boop FA, Jaggar JH: Smooth muscle cell transient receptor potential polycystin-2 (TRPP2) channels contribute to the myogenic response in cerebral arteries. J Physiol 2013;591:5031-5046.

$12 \mathrm{Du}$ J, Fu J, Xia XM, Shen B: The functions of TRPP2 in the vascular system. Acta Pharmacol Sin 2016;37:1318.

13 Zhong X, Fu J, Song K, Xue N, Gong R, Sun D, Luo H, He W, Pan X, Shen B, Du J: The role of TRPP2 in agonistinduced gallbladder smooth muscle contraction. Sci China Life Sci 2015;59:409-416.

14 Jemal A, Bray F, Center MM, Ferlay J, Ward E, Forman D: Global cancer statistics. CA Cancer J Clin 2011;61:69-90.

15 Xiang C, Lv Y, Wei Y, Wei J, Miao S, Mao X, Gu X, Song K, Jia S: Effect of EphA7 Silencing on Proliferation, Invasion and Apoptosis in Human Laryngeal Cancer Cell Lines Hep-2 and AMC-HN-8. Cell Physiol Biochem 2015;36:435-445.

16 Natarajan J, Chandrashekar C, Radhakrishnan R: Critical biomarkers of epithelial-mesenchymal transition in the head and neck cancers. J Cancer Res Ther 2014;10:512-518.

17 Puisieux A, Brabletz T, Caramel J: Oncogenic roles of EMT-inducing transcription factors. Nat Cell Biol 2014;16:488-494.

18 Fuxe J, Vincent T, Garcia de Herreros A: Transcriptional crosstalk between TGF-beta and stem cell pathways in tumor cell invasion: role of EMT promoting Smad complexes. Cell Cycle 2010;9:2363-2374.

19 Leemans CR, Braakhuis BJ, Brakenhoff RH: The molecular biology of head and neck cancer. Nat Rev Cancer 2011;11:9-22.

20 Zhang Z, Yang XF, Huang KQ, Ren L, Zhao S, Gou WF, Shen DF, Sun HZ, Takano Y, Zheng HC: The upregulated alpha-catulin expression was involved in head-neck squamous cell carcinogenesis by promoting proliferation, migration, invasion, and epithelial to mesenchymal transition. Tumour Biol 2015;37:16711681.

21 Sharma T, Radosevich JA, Pachori G, Mandal CC: A Molecular View of Pathological Microcalcification in Breast Cancer. J Mammary Gland Biol Neoplasia 2016;21:25-40.

22 Tepass U, Truong K, Godt D, Ikura M, Peifer M: Cadherins in embryonic and neural morphogenesis. Nat Rev Mol Cell Biol 2000;1:91-100.

23 Beavon IR: The E-cadherin-catenin complex in tumour metastasis: structure, function and regulation. Eur J Cancer 2000;36:1607-1620.

24 Gumbiner BM: Regulation of cadherin-mediated adhesion in morphogenesis. Nat Rev Mol Cell Biol 2005;6:622-634.

25 Kim MJ, Lim J, Yang Y, Lee MS, Lim JS: N-myc downstream-regulated gene 2 (NDRG2) suppresses the epithelial-mesenchymal transition (EMT) in breast cancer cells via STAT3/Snail signaling. Cancer Lett 2014;354:33-42.

26 Bhat FA, Sharmila G, Balakrishnan S, Arunkumar R, Elumalai P, Suganya S, Raja Singh P, Srinivasan N, Arunakaran J: Quercetin reverses EGF-induced epithelial to mesenchymal transition and invasiveness in prostate cancer (PC-3) cell line via EGFR/PI3K/Akt pathway. J Nutr Biochem 2014;25:1132-1139.

27 Gan Y, Shi C, Inge L, Hibner M, Balducci J, Huang Y: Differential roles of ERK and Akt pathways in regulation of EGFR-mediated signaling and motility in prostate cancer cells. Oncogene 2010;29:4947-4958.

28 Willis BC, Borok Z: TGF-beta-induced EMT: mechanisms and implications for fibrotic lung disease. Am J Physiol Lung Cell Mol Physiol 2007;293:L525-534.

29 Syed V: TGF-beta Signaling in Cancer. J Cell Biochem 2016;117:1279-1287.

30 Lo HW, Hsu SC, Xia W, Cao X, Shih JY, Wei Y, Abbruzzese JL, Hortobagyi GN, Hung MC: Epidermal growth factor receptor cooperates with signal transducer and activator of transcription 3 to induce epithelialmesenchymal transition in cancer cells via up-regulation of TWIST gene expression. Cancer Res 2007;67:9066-9076.

31 Stock C, Schwab A: Ion channels and transporters in metastasis. Biochim Biophys Acta 2015;1848:26382646. 


\section{Cellular Physiology Cell Physiol Biochem 2016;39:2203-2215 \begin{tabular}{ll|l} 
DOI: 10.1159/000447914 & $\begin{array}{l}\text { O 2016 The Author(s). Published by S. Karger AG, Basel } \\
\text { www.karger.com/cpb }\end{array}$ \\
\cline { 2 - 3 }
\end{tabular} \\ Wu et al.: TRPP2 Enhances HLSCC Metastasis}

32 Zou Z, Zeng F, Xu W, Wang C, Ke Z, Wang QJ, Deng F: PKD2 and PKD3 promote prostate cancer cell invasion by modulating NF-kappaB- and HDAC1-mediated expression and activation of uPA. J Cell Sci 2012;125:4800-4811.

33 Chen J, Lu L, Feng Y, Wang H, Dai L, Li Y, Zhang P: PKD2 mediates multi-drug resistance in breast cancer cells through modulation of P-glycoprotein expression. Cancer Lett 2011;300:48-56.

34 Jin YT, Kayser S, Kemp BL, Ordonez NG, Tucker SL, Clayman GL, Goepfert H, Luna MA, Batsakis JG, El-Naggar AK: The prognostic significance of the biomarkers p21WAF1/CIP1, p53, and bcl-2 in laryngeal squamous cell carcinoma. Cancer 1998;82:2159-2165.

35 Rubin Grandis J, Melhem MF, Gooding WE, Day R, Holst VA, Wagener MM, Drenning SD, Tweardy DJ: Levels of TGF-alpha and EGFR protein in head and neck squamous cell carcinoma and patient survival. J Natl Cancer Inst 1998;90:824-832.

36 Davis FM, Azimi I, Faville RA, Peters AA, Jalink K, Putney JW, Jr., Goodhill GJ, Thompson EW, RobertsThomson SJ, Monteith GR: Induction of epithelial-mesenchymal transition (EMT) in breast cancer cells is calcium signal dependent. Oncogene 2014;33:2307-2316.

37 Papageorgis P, Lambert AW, Ozturk S, Gao F, Pan H, Manne U, Alekseyev YO, Thiagalingam A, Abdolmaleky HM, Lenburg M, Thiagalingam S: Smad signaling is required to maintain epigenetic silencing during breast cancer progression. Cancer Res 2010;70:968-978.

38 Zhang C, Guo F, Xu G, Ma J, Shao F: STAT3 cooperates with Twist to mediate epithelial-mesenchymal transition in human hepatocellular carcinoma cells. Oncol Rep 2015;33:1872-1882. 